\title{
FESTA DE SÃO PEDRO E SERVIÇOS ECOSSISTÊMICOS CULTURAIS: APRENDIZAGENS DE UM GRUPO PESQUISADOR EM EDUCAÇÃO AMBIENTAL NO PANTANAL
}

Lucia Shiguemi Izawa Kawahara ${ }^{1}$

Michèle Tomoko Sato ${ }^{2}$

Resumo: O presente trabalho busca demonstrar a construção da identidade de um Grupo Pesquisador em Educação Ambiental em diálogo com uma comunidade pantaneira baseado nos princípios da Sociopoética. Na trama metodológica utilizamos, fenomenologicamente, o entrelaçamento das práticas das festas santas com a linguagem da Avaliação Ecossistêmica do Milênio. Procuramos compreender como a comunidade de São Pedro de Joselândia MT consegue manter sua tradição, identidade e, portanto, o amor pela própria terra e os cuidados com ambiente em que vive. Percebemos a presença de uma Educação Ambiental Pós-Crítica vividas pela aprendizagem transgeracional.

Palavras Chaves: Educação Ambiental; Identidade Cultural; Serviços Ecossistêmicos.

\footnotetext{
${ }^{1}$ Secretaria de Estado do Meio Ambiente de Mato Grosso - SEMA. Doutora em Educação pela Universidade Federal de Mato Grosso - UFMT. E-mail: kawahara.lucia@gmail.com

${ }^{2}$ Universidade Federal de Mato Grosso- UFMT. Grupo Pesquisador em Educação Ambiental, Comunicação e Arte - GPEA. Doutora em Ecologia e Recursos Naturais pela Universidade Federal de São Carlos. E-mail: michelesato@gmail.com
} 


\section{Introdução}

A Educação Ambiental normalmente é imaginada pela sua dimensão ecológica em detrimento das expressões culturais. $\mathrm{Na}$ contramão desta perspectiva, o presente texto apresenta os resultados parciais da pesquisa de doutorado que procura compreender as relações das festas tradicionais pantaneiras com o meio ambiente. Uma das questões centrais da pesquisa consiste em compreender a percepção que a comunidade de São Pedro de Joselândia tem sobre os serviços ecossistêmicos culturais, buscando a relação de valorização destes e da territorialidade como princípio de modos alternativos de ser, e estar, no mundo de forma mais sustentável.

São Pedro de Joselândia é um pequeno distrito de Barão de Melgaço MT, localizado a 180 quilômetros de distância da capital mato-grossense, com uma população de aproximadamente 2.562 habitantes $^{3}$, cercada pelas águas dos rios Cuiabá e São Lourenço. São Pedro de Joselândia é composto pelo coletivo de sete comunidades: a maior de todas, São Pedro; Mocambo; Pimenteira; Retiro São Bento; colônia Santa Isabel; Capoeirinha e Lagoa do Algodão.

Esta pesquisa, com interface na metodologia da Avaliação Ecossistêmica do Milênio - AEM da Organização das Nações Unidas - ONU, procurou estabelecer o estudo das relações dos Serviços Ecossistêmicos de Provisão, Suporte, Regulação e Cultura com o bem-estar humano, sustentado pelos princípios da Educação Ambiental que prima pela inclusão e justiça socioambiental. O relatório da AEM define o Serviço Ecossistêmico Cultural como benefício não material (patrimônio imaterial) obtido pelos ecossistemas na relação do ser humano com o ambiente (SARUKHÁN; WHYTE, 2005).

Optamos pela adoção da Sociopoética como uma das bases metodológicas da pesquisa, compreendendo que a Sociopoética é "uma forma de compreender que o mundo não é só explicado pelos fenômenos naturais, mas propõe uma produção do conhecimento mais coletiva, valorizando as pessoas que estão fora dos espaços universitários ou das famosas instituições; de pesquisas, buscando um diálogo com comunidades" (SATO; LEITE MEDEIROS; RIBEIRO, 2002, p. 60). Os membros do grupo em ação coletiva e dialógica realizaram observações, entrevistas não direcionadas e direcionadas, questionários, oficinas com vistas à construção conjunta de conhecimentos, práticas e valores propiciadores de uma melhor qualidade de vida com sustentabilidade socioambiental, ainda que o conceito de qualidade de vida esteja longe de ser consenso.

A pesquisa tem demonstrado que o diálogo em torno das festas desta comunidade pantaneira abre possibilidades de melhorarmos as reflexões

\footnotetext{
${ }^{3}$ Dados IBGE, Censo 2010, disponível em:

http://www.ibge.gov.br/home/estatistica/populacao/censo2010/default.shtm. Acessado em 22 de abril de 2013.
}

Revbea, São Paulo, V. 10, N 1: 221-240, 2015. 
relativas à importância do Pantanal. Chama-nos atenção a necessidade de ampliarmos ainda mais os momentos de aprendizagem coletiva sobre o bioma, sobre a biodiversidade, e sobre a cultura local, pois a comunidade pantaneira demonstra saber e ter formas peculiares de bem estar, necessitando de Políticas Públicas específicas e diferenciadas para melhorar a sua qualidade de vida. Faz-se, portanto, fundamental continuarmos a pesquisa e produzirmos materiais e momentos educativos para fortalecer a produção de saberes e parcerias que possam auxiliar na busca pela melhoria da qualidade de vida dos pantaneiros e na conservação do Pantanal.

\section{Contexto}

Em Mato Grosso, com a proximidade do mês de junho, é sinalizada pelo calendário universal, a chegada do inverno no hemisfério sul do planeta, mesmo em Cuiabá, em meio aos trópicos, no centro geodésico da América do Sul o referido calendário sugere a chegada do frio. Nosso cotidiano é marcado pela relação com a mídia, vitrines, propagandas, imagens, onde os diversos textos e contextos levam-nos a acreditar em um gélido inverno. O "clima" ao nosso redor nesta época do ano se estrutura em aromas, texturas, sonoridade e sabores candentes para suprir supostas necessidades inerentes à estação do frio pautado no calendário literalmente norteado pelos padrões eurocêntrico ou da hegemonia do hemisfério norte (SOUZA SANTOS, 2005). Basta uma volta pelo centro comercial ou pelos shoppings centers para depararmos com os preparativos para recebermos um intenso frio em um suposto inverno que se aproxima. No entanto, um minuto de reflexão seria suficiente para percebermos que há um sol escaldante e um azul infinito de um céu sem nuvens. $O$ termômetro na capital mato-grossense, apesar de oficialmente estarmos no inverno, mantém os números em torno dos trinta graus centígrados e de fato vivenciamos nesta época do ano, a aproximação da escaldante da estação de seca no Centro Oeste brasileiro.

A transnacionalização é alcançada pela mundialização dos meios de informação e de comunicação que, com potente indústria midiática do ócio garante a "venda" de ícones e sistemas universais de valores e consumismo (HERNANDEZ, 1998). O modelo de vida globalizado pautado na lógica desenvolvimentista, sustentado pelos princípios neoliberais e universalizado pelos interesses mercadológicos, quebra as fronteiras e padroniza identidades, instituindo critérios globais de interesse:

Quanto mais a vida se torna mediada pelo mercado global de estilos, celulares e imagens, pelas viagens internacionais, pelas imagens da mídia e pelos sistemas de comunicação globalmente interligados, mais as identidades se tornam desvinculadas - desalojadas - de tempos, lugares, histórias e tradições específicos e parecem "flutuar livremente" (HALL, 2006, p. 75). 
Testemunhamos uma crise socioambiental mundial causada pela estagnação dos recursos naturais e desenfreado consumismo de forma globalizada, acompanhado de um quadro global de exclusão e injustiças sociais alarmantes inerentes à crise socioambiental global:

O significado mais profundo transmitido pela idéia da globalização é o do caráter indeterminado, indisciplinado e de autopropulsão dos assuntos mundiais, [...] a GLOBALIZACAO é a nova desordem mundial (BAUMAN, 1999, p. 67).

Urge tecermos no bojo da Educação Ambiental - EA novas formas de vida e caminhos alternativos ao consumismo desenfreado. Urge recuperarmos e dialogarmos com os saberes menosprezados pela ciência iluminista. Faz-se imperativo a retomada e a valorização das relações perdidas pelo cartesianismo que distanciou o ser humano da natureza na ilusão do desenvolvimento ${ }^{4}$ neoliberal, para sermos capazes de compreender que não há necessidade de casacos de peles e botas de couros forradas para se viver a estação de seca em Mato Grosso.

Tal empreitada se torna possível se consideramos a complexidade dos fenômenos, restaurando a indissociabilidade das relações axiomáticas, praxiológicas e epistemológicas da educação; se ponderarmos sobre a interrelação da territorialidade, temporalidade e identidade dos povos; recuperando o respeito às multirreferencialidades para a construção de sociedades mais justas e sustentáveis.

Compreender a maneira pela qual as identidades se projetam os territórios cotidianos, entrelaçadas no bojo da dinâmica socioambiental coletiva, pode ser um indicativo social e antropológico que corrobora com a necessidade de aliar cultura a natureza à formação de políticas públicas (SANTOS; SATO; ZANIN; MOSCHINI, 2009, p. 33).

Segundo os dados da AEM, coordenada pelas Nações Unidas que objetivou a avaliação das consequências das mudanças nos ecossistemas e a relação com o bem estar humano, vivemos uma situação de degradação ambiental inédita na história da humanidade. Os estudos, da AEM realizados por mais de 1300 cientistas de 96 países do mundo inteiro, revelam que os 50 últimos anos acarretaram nos ecossistemas, perdas substanciais $\mathrm{e}$ irreversíveis. Não se nega os ganhos de bem-estar humano, no entanto os

4 “O termo 'des-envolvimento' foi utilizado por Sato (2001) ao questionar o contexto etimológico desta palavra, cujo termo é composto por dois radicais latinos - 'des' e 'envolvere'. O prefixo 'des' sugere a negação a alguma coisa. Assim, des-envolver é negar o envolvimento que cada povo e cada cultura (habitantes) mantêm com seu território (habitat) e com seu modo de vida (hábitos)". (SILVA, 2011, p. 134)

Revbea, São Paulo, V. 10, Nº 1:221-240, 2015. 
resultados da avaliação apontam grandes problemas: $60 \%$ dos serviços ecossistêmicos têm sido utilizados de forma não sustentável, os impactos causaram mudanças não lineares nos ecossistemas e a população mais pobre sofrem muito mais os efeitos negativos da degradação ambiental, resultando no aumento das desigualdades e injustiças socioambientais.

A proposta metodológica da AEM é a divulgação, sensibilização e responsabilização dos diversos seguimentos da sociedade em prol da recuperação e desaceleração da degradação ambiental, focalizando a compreensão da complexa relação do sistema de serviços ecossistêmicos, a saber: Serviço de Suporte, Regulação, Provisão e Cultural ${ }^{5}$. O bem estar humano está intrinsecamente dependente dos quatro serviços ecossistêmicos que por sua vez estão interligados com outros fatores constituintes como os ambientais, econômicos, sociais, tecnológicos e culturais.

Apesar da importante contribuição da AEM, compreendemos que em meio às incertezas, inerente à pós-modernidade, devemos manter claro que modelos e padrões globais podem não corresponder à realidade local e, portanto, precisamos criar alternativas de sustentabilidade e compreensão das necessidades específicas de cada lugar. Em outras palavras, podemos nos orientar por propostas internacionais, mas necessariamente elas devem se adequar à realidade local, já que por serem singulares, as biorregiões possuem suas particularidades e saberes que emolduram novos cenários, ainda que não se perca a noção globalista do pensamento.

Coadunamos com Paulo Freire que nos convida ao exercício da açãoreflexão-ação para a construção de contextos pautados na ética da responsabilidade onde "a ênfase está na entrega: cuidar do outro humano e o outro como humano, com uma atenção permanente e afetuosa" (SAUVÉ, 2005, p.32). Assim, acreditamos que por meio de uma Educação Ambiental cheia de "confetos", em um espaço híbrido entre conceitos e afetos, com a proposta de aprender na coletividade, com prazer, abriremos as possibilidades de encontrarmos respostas aos desafios existentes (MATURANA, 2009; FREIRE, 1996).

Ao buscarmos compreender as formas de organização e a ação do ser humano no mundo, o desafio se instaura na recuperação da capacidade do pensamento complexo, pois na modernidade perdemos a compreensão do processo como um todo e consequentemente o poder da decisão pela fragmentação do trabalho e do ensino (SILVA, 2005). Por entendermos que a Educação Ambiental não é neutra e deve propor a compreensão crítica e complexa das questões socioambientais e a superação da visão reducionista e dicotomizada da modernidade (VIÉGAS, 2005; BAUMAN, 2005).

\footnotetext{
${ }^{5}$ Para saber mais: http://www.millenniumassessment.org/en/index.aspx (acesso em 30/abril/2014). http://www.greenfacts.org/en/ecosystems/ (acesso em 30/abril/2014). http://www.ufmt.br/gpea (acesso em 30/abril/2014).
} 
$\mathrm{Na}$ Educação Ambiental o movimento se distancia das certezas e busca criar novas possibilidades no próprio cotidiano, considerando a incompletude humana e fortalecendo as relações, pois se faz necessário considerar "a subjetividade, as relações intersubjetivas e a fundamentação como um conhecimento não linear, fazendo analogia com a metáfora da rede para compreender a vida e o conhecimento" (TRISTÃO, 2009, p.06).

Não acreditamos em uma cultura nacional ou homogeneização de identidades. Compreendemos que existem diferentes grupos ou comunidades com identidades próprias, tecidas na urgência de um mundo pós-moderno acelerado e com múltiplas transformações. (HALL, 2005; BHABHA, 1998; BAUMAN, 2005). Enfatizamos a importância do entrelaçamento do respeito às diferentes identidades e do permanente processo de construção de valores, comportamentos e conceitos, dimensões axiológicas, praxiológicas e epistemológicas da Educação Ambiental respectivamente (PASSOS; SATO, 2005).

\title{
Desenvolvimento
}

A Educação Ambiental deve dar audiência às vozes das diferentes comunidades para conhecer, não verdades únicas ou receitas, mas possibilidades de diferentes formas de ser e estar no mundo atual. Defendemos a necessidade de nos livrarmos das amarras da modernidade que buscou a universalização e a padronização de valores como princípio para a implantação e implementação de valores universalizantes e consequente coerção dos modos de vida.

\begin{abstract}
A supercontextualização do conhecimento é uma garantia de que os saberes ambientais não sejam reduzidos a abstrações manipuladas pelo poder imperial da falsa democracia do consumo e das representações (SATO; GAUTHIER; PARIGIPE, 2005, p.113).
\end{abstract}

Ao almejarmos alcançar na pesquisa em Educação Ambiental, não apenas a investigação, mas a construção de conhecimento e práticas com as comunidades para coletivamente produzir as transformações necessárias, optamos estabelecer uma pesquisa fenomenológica com expressão descritiva dos sentidos tramados e densos que animam e permitem a produção da cultura e projetam uma teia de possibilidades infinitas e criativas. Buscamos alcançar na pesquisa em Educação Ambiental não apenas a investigação, mas a construção de conhecimento e práticas com as diferentes comunidades para, então, coletivamente produzirmos as transformações necessárias. E nesta pesquisa, optamos pela Sociopoética que poderá nos conduzir pelos labirintos da investigação. 
A "Sociopoética", uma forma de compreender que o mundo não é só explicado pelos fenômenos naturais, mas propõe uma produção do conhecimento mais coletiva, valorizando as pessoas que estão fora dos espaços universitários ou das famosas instituições de pesquisas, buscando um diálogo com comunidades aceitando a intuição, a imaginação, as sensações, os gestos e também a emoção (SATO; LEITE; MEDEIROS; RIBEIRO, 2002, p.60).

Nesta perspectiva, optamos por caminhar pelo contexto da nossa pesquisa, orientados pelos cinco princípios apresentado por Sato, Gauthier e Parigipe (2005, p. $100-101 ; 109$ e 110). Na abertura de caminhos ao longo do labirinto da pesquisa, percorremos por tais princípios inscritos nas esferas das teorias (episteme), vivências (práxis) e valores (axioma), reinterpretando, construindo e tecendo as compreensões das possibilidades, conforme segue:

Primeiro Princípio: Todo grupo pode tornar-se um "grupo sujeito", isto é, um coletivo pode ser o próprio pesquisador com objetivos também de aprendizagem.

Considerando o primeiro princípio e respeitando a relevância dos grupos sociais, buscamos realizar o diálogo direto com a comunidade de São Pedro de Joselândia para constituição de um mosaico de saberes pela conversação e vivências. Na Educação Ambiental aspiramos à compreensão das mudanças e valorização de práticas culturais, conhecimentos e expressões com que se identificam os membros das comunidades, bem como a percepção que os mesmos têm acerca do ambiente onde vivem.

As percepções que os membros da comunidade têm sobre sua cultura são tão valorosas quanto os conhecimentos científicos à elaboração do presente trabalho e todos fazem parte de um uno que expressará, neste tempo e espaço, as nossas necessidades e anseios. Formamos assim um Grupo Pesquisador sem diferenciar ou hierarquizar os teóricos, os sujeitos da pesquisa, pesquisador.

Segundo Princípio: É preciso reconhecer as diferentes formas de produção do saber e filosofias próprias de cada cultura, bem como os processos de resistência na produção e de que maneira este grupo lida com as informações, interpretação e socialização da pesquisa.

Tentamos demonstrar a incorporação do segundo princípio, decidindo não separar nosso trabalho, em parte conceitual de fundamentação teórica de um lado e de outro, os saberes populares da comunidade pantaneira. Buscamos sistematizar esta tese construindo nossos conhecimentos em constante diálogo com os teóricos do acervo bibliográfico, com os pesquisadores do GPEA e da UFMT, com os membros da comunidade de São 
Pedro de Joselândia, sem segregá-los, mas incluindo-os como sujeitos deste grupo pesquisador.

Nesta pesquisa, o fio condutor da conversação com os agentes que nos ofereceram material para reflexão e construção da tese é a Festa. Buscamos conhecer a expressão cultural da comunidade de São Pedro de Joselândia e suas formas de interação e relações no contexto das celebrações de suas Festas Tradicionais. Mergulhamos nos livros, nas festas e em nós mesmos à procura das possibilidades de um mundo mais fraterno e coletivo. "Se $o$ conhecimento leva a alguma parte, é ao entendimento, à compreensão, e isso leva a uma ação harmônica e ajustada com os outros e o meio" (MATURANA; YANEZ, 2009, p.55).

Terceiro Princípio: Para além da racionalidade, assegura-se a utilização do corpo inteiro na produção do conhecimento, incluindo a intuição, sensualidade, emoção, gestualidade, olhares, tatos ou campos de silêncios.

O exercício do terceiro princípio da Sociopoética, fazer pesquisa de corpo inteiro, foi realizado o tempo todo, mas em São Pedro de Joselândia, especificamente, iniciamos pela observação participante dos ritos, comemorações e manifestações culturais. A imersão no contexto pantaneiro e, posteriormente, nos dias festivos é uma experiência que se faz com todos os sentidos possíveis do nosso corpo, da nossa mente e da nossa alma.

A beleza do Pantanal no tempo das águas nos tira o fôlego, e lágrimas da alma correm pelo rosto que contempla a vida na imensidão do verde e azul, colorido pelas incontáveis flores que embelezam ainda mais a paisagem. $O$ cheiro de mata queimada e a ardência da pele na estação de seca são inenarráveis pela boca sedenta e eternamente desidratada neste período. É impossível deixar o passional de lado, pois é imenso o conforto e o acolhimento generoso do povo pantaneiro. Se as boas-vindas nos cativam em dias normais, quem dirá nas datas festivas.

Não só durante a imersão nas águas e terras pantaneiras, mas no cotidiano acadêmico, o exercício de incluir a dimensão passional, espiritual, bem como admitir nossas próprias criatividades, ousadias, limites e fraquezas provenientes das nossas histórias de vida constituiu um desafio hercúleo. Foi muito difícil quebrar a lógica cartesiana tão arraigada em nosso ser e nos permitir perceber o mundo de forma diferenciada e exercitar aquilo com que nos presenteiam Sato e Passos (2006, p.19): "A poética excita e impulsiona a Educação Ambiental para que as ideias e as emoções, tomando nossa corporeidade, fluam na liberdade do movimento, banhadas nas luzes e nas sombras das iconografias e das linguagens de cada ser".

Revbea, São Paulo, V. 10, Nº 1: 221-240, 2015. 
Quarto Princípio: Potencializar a arte como processo que contribui significativamente para a formação, não apenas em seu lado lúdico ou estético, mas também como momento de criação e imaginação, além de sonhos que possam estar nos jogos de aprendizagens (episteme e praxiologia).

Especificamente nesta pesquisa, focalizamos as festas santas do Pantanal, que são, por si, momentos de explosões e transgressões, pois: "Toda festa acontece de modo extra cotidiano, mas precisa selecionar elementos característicos da vida cotidiana. Toda festa é ritualizada nos imperativos que permitem identificá-la, mas ultrapassa o rito por meio de invenções nos elementos livres" (AMARAL, 2001, p.19). Provavelmente a maior força e boniteza do presente trabalho se constituem justamente no crescimento e mudança na forma de SER em interação com o OUTRO e com o MUNDO em que vivem as pessoas envolvidas no processo das celebrações.

A festa revelou ser um processo fundamental para se repensar 0 currículo no contexto da educação das comunidades pantaneiras. Esta prática revela exatamente a possibilidade de transgressão e alcance de aprendizagens significativas de forma criativa e aberta à liberdade do imaginário dos integrantes da cultura peculiar de São Pedro de Joselândia.

Quinto Princípio: A construção de "confetos (conceitos com afetos)" que estimule o sentido ético, político e filosófico não apenas por meio de teorias ou métodos, mas também de valores, espiritualidade ou fé.

A proposição do quinto princípio é praticada, pensada e proposta ao longo do processo da pesquisa fenomenológica, numa escuta sensível às alternativas apresentadas, traduzindo-as em possibilidades de construção conjunta de programa de educação ambiental como forma de implementar e avaliar o que atualmente pode apenas se constituir em "estado de coisas" nas Políticas Públicas de Educação Ambiental na atualidade.

Assumimos por isso a possibilidade sociopoética, por estarmos cientes de que a imagem poética não é mero parêntesis no interior de uma pesquisa, ela é historicamente emoldurada na emergência de uma projeção política (SATO; PASSOS; ANJOS; GAUTHIER, 2004, p.18).

A construção epistemológica de forma amorosa e comprometida politicamente foi uma aprendizagem realizada sempre na coletividade. Todas as pesquisas de campo ocorreram na companhia de integrantes do GPEA. Colóquios de discussões e aprofundamento teórico foram realizados na coletividade. Ressaltamos que até mesmo os estudos bibliográficos feitos no isolamento corporal, não constituem isolamento efetivo, pois a leitura dos 
textos sempre esteve sendo feita pela pesquisadora de identidades múltipla, ou híbrida, como asseguraria o teórico cultural Stuart Hall (2006).

\section{Alguns Resultados}

Procurando conhecer um pouco mais sobre o jeito de viver desta comunidade pantaneira, dialogamos com os moradores de São Pedro de Joselândia e surpreendemo-nos com a alegria desta gente e chamou-nos especial atenção os animados relatos sobre as inúmeras celebrações de festas santas que acontecem ao longo do ano (Tabela 1). As observações em São Pedro de Joselândia nos reafirmam a convicção de que as festas nesta comunidade fazem parte da estrutura do cotidiano e está integrado na sua cultura como espaço concreto de construções e fortalecimento das relações sociais. (ÁGUAS, 2012).

Tabela 1: Lista das Festas Santas da Comunidade de São Pedro de Joselândia.

\begin{tabular}{llll}
\hline \multicolumn{1}{c}{ Mês } & \multicolumn{1}{c}{ Festa } & Dia & \multicolumn{1}{c}{ Realização } \\
\hline Janeiro & São Sebastião & 20 & Familiar (Pimenteira) \\
\hline Fevereiro & Carnaval & - & Familiar (São Pedro) \\
\hline Março & São Bento & 21 & Familiar (Pimenteira) \\
\hline Abril & São Benedito & 03 & Familiar (não há mais) \\
\hline Maio & Coração de Maria & - & Só novena sem festa \\
\hline Junho & São Pedro & 29 & SORTEIO (São Pedro) \\
\hline Julho & Sant'Ana & 26 & SORTEIO (São Pedro) \\
\hline Agosto & São Roque & 16 & Familiar (não há mais) \\
\hline Setembro & São Cosme e Damião & 25 & Familiar (São Pedro) \\
\hline Outubro & Nossa Senhora Aparecida & 12 & Familiar (Pimenteira) \\
\hline Novembro & Santa Catarina & 25 & Familiar (não há mais) \\
\hline Dezembro & Santa Luzia & 12 & Familiar (Pimenteira) \\
\hline & Senhor Menino & 25 & SORTEIO (São Pedro) \\
\hline
\end{tabular}

Fonte: Entrevistas com ex-festeiros e comunidade de São Pedro de Joselândia.

Dentre todos os eventos listados na Tabela 1, a festa de São Pedro é considerada pelos moradores, como uma das maiores expressões culturais desta comunidade. A comunidade é unânime em indicar esta celebração como o evento mais importante da localidade. Esta comemoração reúne todos os ingredientes necessários à construção de uma identidade comunitária, pois agrega num só evento, o trabalho coletivo e a arte nas mais variadas formas, conjugadas em torno de uma fé compartilhada (BHABHA, 1998; HALL, 2006).

A comida farta durante a festa - serviços de provisão, regulação - é distribuída gratuitamente, o seu preparo e a sua oferta na coletividade, expressam os valores e os conhecimentos específicos desta comunidade, observamos neste ritual, a presença da aprendizagem transgeracional. Conhecimentos e valores são transmitidos dos mais velhos anciões às gerações subsequentes e percebemos que as festas: 
Constituem um domínio em que a tradição e a inovação têm a mesma importância, em que o presente e o passado se entrelaçam para satisfazer a necessidade do momento, trazer a alegria de um instante e convir às circunstâncias (CERTEAU; GIARD; MAYOL, 1996, p.212).

Outro evento fundante é a missa realizada na Festa de São Pedro. Durante esta festividade especificamente, o padre da comarca à qual São Pedro de Joselândia pertence se faz presente para a celebração da missa. Ocasião em que são realizados os batizados, casamentos, crismas; ritos considerados de fundamental importância aos cristãos, conferindo-lhes o pacto da fraternidade, o sentimento de pertença e o estatuto de plena cidadania e ser social (BAUMAN, 2003; HALL, 2006).

Assim, as festas demonstram ser um momento privilegiado de estudo à compreensão desta comunidade, pois nela existem as "formas de fazer" pantaneiro, algumas "táticas" e saberes construídos coletivamente dos quais a Educação Ambiental é defensora: a "criatividade cotidiana" como nos ensina Certeau (1996) é imprescindível à construção de sociedades sustentáveis (SATO, 2011).

Uma das formas de organização de resistência à lógica globalizada do mundo moderno pode ser encontrada na tradição da organização das festividades em Joselândia. As festas desta comunidade possuem uma estrutura sócio-cultural de solidariedade, coletividade, honra e cumprimento dos compromissos sem a necessidade de leis ou promissórias. Este contrato social e as práticas organizacionais das festas desta comunidade revelam um tradicional laço pantaneiro de fundamental importância na manutenção das relações comunitárias da localidade (GEERTZ, 2001; PASSOS, 2010).

Como exemplo das práticas tradicionais de manutenção da identidade e cultura tradicional desta comunidade, podemos citar o sorteio do festeiro. $O$ festeiro é a pessoa sorteada para organizar, patrocinar e promover a festa religiosa. O sorteio do festeiro do ano seguinte acontece ao final das celebrações da festa que se finda. Torna-se incumbência do novo festeiro sorteado, finalizar a comemoração em curso e organizar a do ano subsequente. Neste ritual, percebemos a sabedoria da transferência de responsabilidade e do pacto comunitário em manter a tradição herdada.

Outra importante práxis revela um saber específico dos pantaneiros: a arrecadação da esmola ${ }^{6}$ que acontece no ano que antecede a festa para a qual os donativos são arrecadados alguns meses após o sorteio do festeiro. A

\footnotetext{
${ }^{6}$ Esmola é outro rito importante na festa, é o peditório por todas as casas da comunidade para arrecadar donativos e contribuições em espécies ou produtos diversos para a realização da festa santa. Ritual onde "os festeiros percorrem as ruas da cidade levando de casa em casa a bandeira dos santos e recebendo donativos que serão transformados em alimentos para serem servidos no dia da festa propriamente dita" (FREITAS, 2001, p.206).
} 
mesma é realizada ainda no tempo da seca, momento em que o organizador sorteado ainda pode passar nas sete comunidades, de casa em casa, anotando a doação prometida numa simples caderneta. Quando as águas da chuva fazem surgir as "estradas de água" separando as casas, as pessoas da comunidade continuam ligadas umas às outras, enlaçadas pela esmola prometida/ofertada, mantendo assim a identidade de pertença e comprometimento pela devoção e fé comum (CERTEAU, 1996; BAUMAN, 2003; HALL, 2006).

Quando as águas novamente baixarem - serviço de regulação, é tempo de se lançar novamente às "estradas de chão" e coletar as esmolas prometidas, conjugar trabalhos e reunir as pessoas que comungam da mesma fé e compromissos à realização da festa de santo.

"Agente começa a fazer doce um mês antes, um mês antes, para curtir bem o doce. Maio começa, lutando, trabalhando para dar o ponto certo, para dar essa festa" (D. Maria de Oliveira, cozinheira voluntária nas festas).

São Pedro de Joselândia também sabe ajustar a tradição de longas datas às novas demandas e desejos trazidos pelas facilidades da modernidade, por exemplo, a energia elétrica que apenas há cinco anos chegou naquelas terras. A eletricidade influenciou diretamente na organização da rotina desta comunidade, inclusive nas festas. Atualmente, com a chegada do som eletrônico, a primeira noite não é mais celebrada apenas com a cantoria dos Cururueiros.

De pouco a pouco, começaram a introduzir o baile dançante desde a primeira noite com a contratação de bandas musicais. Assim, devido à idade avançada dos cururueiros, bem como pelos anseios dos jovens em promover a diversão acima da celebração religiosa e recentemente, com a chegada da energia elétrica, o rito do Cururu tem sido resumido apenas ao momento de levantamento e arreamento do mastro com a bandeira do Santo. No entanto, apesar destas mudanças, os participantes da festa de São Pedro continuam afirmando que o ponto culminante da festa é a chegada dos cururueiros, seguido pelo levantamento do mastro e pela própria celebração da missa.

"Eu venho lá de Cuiabá todo ano, voltei para batizar, por que nossa missa é diferente, é assim que tem que ser, não acostumei com a missa da cidade, aqui é diferente e volto todo ano". (D. Luiza, ex-moradora de São Pedro de Joselândia).

"Não tem problema mudar, todo mundo precisa... o mais importante é a fé, a festa é a fé, é doença curada, depressão curada e ai, tem festa boa, tem fartura, música e alegria”. (D. Celina, ajudante de cozinha na festa). 
Observamos que a organização da festa mostra a relação direta deste serviço cultural - Festa de São Pedro, com os demais serviços de provisão e regulação, uma vez que nela são utilizadas palhas, madeiras, cipó, madeira do mastro, plantas ornamentais, lenhas, argilas. Sem mencionar a rica diversidade de guloseimas produzidas a partir das frutas do cerrado e inúmeros pratos típicos pantaneiros utilizando-se a criação de animais galinhas, gado, suínos e seus derivados. Os serviços de suporte e regulação anteriormente apresentados na lógica organizacional realizada de acordo com as estações de seca e chuva confirmam novamente a forte relação da festa com o meio ambiente e não com os ditames da mídia capitalista.

Ao verificar tais interligações dos serviços ecossistêmicos apresentados pela Avaliação Ecossistêmica do Milênio, percebemos que os pantaneiros possuem hábitos construídos na relação direta e íntima com o meio em que vivem, demonstrando saber alternar as táticas do cotidiano conforme a época Ihes exige, revelando um saber flexível mantido na tradicional forma de viver e ser desta comunidade.

A presente pesquisa, apesar de não buscar essencialmente a avaliação de tais serviços, procurou compreender a identidade dos pantaneiros nas expressões culturais dentro das orientações da AEM. No entanto, abrimos parênteses para registrar que desejamos transcender o entendimento de "serviços", almejando um diálogo de "trabalhos" realizados, ao invés de "serviços" prestados ao ser humano, sugerindo uma perspectiva de relações mútuas.

Propomos a relação de "trabalhos" trocados dentro dos ecossistemas, com uma expectativa menos antropocêntrica, com fortes vícios da modernidade que dicotomiza os prestadores de serviços e consumidores de serviços, ou até mesmo a hierarquização de categorias que prima apenas pelo bem-estar humano, sem considerar os outros seres. Desejamos com esta proposição abarcar muito mais do que o antropocentrismo, mas essencialmente a compreensão das relações complexas estabelecidas.

Aos educadores ambientais "parece ser obrigação, assim, tentar reinventar alguns novos caminhos que fujam do modelo imposto ao alvorecer de novas auroras científicas" (SATO, 2011, p.564).

O Sr. Joselito da Silva, ex-festeiro, confirma a importância destas comemorações, assinalando inclusive que elas têm uma identidade própria, diferenciando-se de outras festas de localidades distintas do Pantanal. Tal afirmação revela uma cultura que resiste aos tentáculos da universalização cultural, típica da globalização (SOUZA SANTOS, 2005; BAUMANN, 1999). Segundo Sr. Joselito, as festas desta região são tipicamente pantaneiras e não se confundem com as tradições de outras regiões.

"É, é pantaneira, estas (festas) aqui é pantaneira! Cada um tem uma tradição diferente, né?! Desde a dança, é, desde a dança é diferente, cada um tem um, do nordeste é diferente, nosso 
aqui já tem diferença, ai mesmo de Cuiabá, a dança de siriri é diferente daqui" (Sr. Joselito da Silva, festeiro de 2008).

As relações das festas com o meio ambiente não são percebidas com facilidade pelos moradores da comunidade. Observamos que ao questionarmos se as celebrações teriam alguma relação com a natureza, sobre os benefícios ou malefícios que estas comemorações causam à natureza, de imediato, muitos afirmam que não há muita relação. No entanto, quando conversamos com mais vagar, dialogando sobre as provisões ofertadas pela terra, começam a lembrar do milho, arroz, feijão, mandioca e tantas outras culturas retiradas das plantações; também elencam a madeira, a palha, os mastros utilizados nas festas. Devagar, começam a refletir melhor e revelam o saber e o fazer que desde muito praticaram no local, demonstrando as ligações existentes entre a cultura popular local e o meio em que vivem (GROOT; RAMAKRISHNAN, 2005).

O Sr. Joaquim, um dos ex-festeiros mais idosos de São Pedro de Joselândia, demonstra o quanto as festas, apesar de ser momento de diversão, são também representativas da religiosidade da comunidade, da união e 0 sentimento de dever e a devoção do povo a Deus:

\begin{abstract}
"A festa é para nós adorar! Deus deixou a festividade pra nós, para diversão do povo, por que Deus deixou, você vai fazer a festa, então para louvar Ele. Não é dizer que é só por que nós que queremos fazer, é um dever né?! Ai a senhora faz, tem uma devoção com o Senhor Divino, e diz, 'oh eu vou festejar o Senhor Divino' e então todo ano a senhora festeja. Deus deixou a brincadeira, a diversão, a festividade, a reza, o adorar o Santo" (Sr. Joaquim Santana da Silva - festeiro de 1991).
\end{abstract}

Percebe-se então que a festa de São Pedro de Joselândia comunga em torno do seu ritual todas as categorias apontadas na pesquisa realizada pela AEM/ONU como dimensões dos Serviços Ecossistêmicos Culturais, a saber: tradição cultural; identidade; valores estéticos; de inspiração; valores religiosos e espirituais, recreação e turismo. Reafirma-se a intrínseca relação dos serviços culturais com os demais serviços de provisão, suporte e regulação, pois como sabiamente afirmou o Sr. Joaquim:

"Esta festa do pantanal, quer dizer que é do povo, é do pantanal, é do povo daquele setor, é desse povo, daquele povoado. É o que existe dentro do pantanal, é o que dá pra fazer a festa, ali pode fazer, tem arroz, tira o arroz, tem milho, tira milho e faz fubá, faz biscoito que é daqui do pantanal, a mandioca é do pantanal, o gado é daqui do pantanal, o porco é daqui do pantanal e aqui é tudo, tem tudo" (Sr. Joaquim Santana da Silva - festeiro de 1991).

Revbea, São Paulo, V. 10, N 1: 221-240, 2015. 
Conseguimos ao longo dos anos que estivemos na comunidade, observar, conversar a respeito da Festa e conseguimos entender as relações dela com os constituintes do bem-estar apresentados pela AEM. Elaboramos um quadro com o demonstrativo da força de relação das seis categorias do Serviço Cultural com os referidos componentes de formação do bem-estar para tentar demonstrar o quão importante é a Festa de São Pedro para os moradores de São Pedro de Joselândia.

Se apenas pegássemos os dados do censo do IBGE ou qualquer outro indicador para entender São Pedro de Joselândia, provavelmente enxergaríamos esta comunidade rural como pobre e desprovida do bem-estar, pois todos os constituintes do bem-estar seriam avaliados de forma bastante negativa. Em São Pedro de Joselândia não há nenhuma estrutura pública de segurança, não há sequer um posto policial; os números de emprego ou renda que poderiam revelar a situação de provisão de material básico são baixos; no tocante à saúde apesar da existência de posto de saúde, a comunidade não tem atendimento médico em seu próprio território.

No entanto, foi possível perceber, conforme apresentamos anteriormente pelas informações coletadas no questionário aplicado pelo GPEA, a própria comunidade confirma que se sente satisfeita com a vida que tem ali. Existem inegavelmente, desejos por aquisições de padrões urbanas de vida, principalmente após a chegada da energia elétrica que trouxe conjugado num só pacote: a comodidade e consumismo. Ainda assim, a maioria declaram que continuam na comunidade por opção.

Se procurarmos entender como os moradores de São Pedro de Joselândia conseguem se sentir felizes mesmo vivendo com índices tão baixos dos constituintes do bem-estar compreenderemos ser pessoas realmente diferenciadas do padrão de vida globalizado da atualidade. Utilizaremos os mesmos constituintes do bem-estar apresentados pela AEM para mostrar que na relação com a Festa, os indicadores oficiais do censo não servem como critério de avaliação. Tais constituintes (segurança, saúde, material básico, relações sociais) pensados no contexto das celebrações revelam bem-estar jamais previsível pelos números de um levantamento censitário e veremos, à revelia dos indicadores oficiais, o quão bem vivem os pantaneiros de São Pedro de Joselândia.

"Ah não é bom...porque essa [a festa de São Pedro] desde nosso nascimento já tínhamos ela, então se ela acabar tem que acabar o mundo..." (D. Maria Benedita da Conceição, 87 anos).

Primeiramente, é preciso enfatizar, mais uma vez, que foi possível observar a existência de todas as seis categorias que compõem os trabalhos culturais na organização, estruturação e realização da Festa de São Pedro e Revbea, São Paulo, V. 10, N 1: 221-240, 2015.

revista brasileira educação ambiental 
estas, por sua vez, possuem relação direta com todos os constituintes do bemestar. Os moradores de São Pedro de Joselândia têm orgulho de realizar a Festa que já é referência no Pantanal. Ouçamos as palavras dos festeiros:

\begin{abstract}
"A festa é muito boa né?! Esse ano o pessoal fala: 'ah eu fui na festa do Pantanal! Esse ano a festa foi boa, no outro ano eu vou'. Então, todo ano o pessoal vem né, igual o pessoal da outra cidade mesmo, aí de Livramento, o pessoal de lá diz: 'vou lá conhecer o Pantanal né, vou lá conhecer a festa, porque aqui é diferente né?!" (Sr. José Dias, 70 anos, festeiro de 2006).
\end{abstract}

O bem-estar na comunidade existe, pois os moradores, eles próprios são os responsáveis por produzir e assegurar os ditos constituintes do bemestar (segurança, materiais básicos, saúde, relações sociais). Em outras palavras, em São Pedro de Joselândia os tais componentes não são aguardados como direito ou como política pública que lhes serão ofertados pelo governo. Como comunidade abandonada pelos poderes públicos, eles próprios trataram de garantir tais constituintes do bem-estar.

Conseguimos ao longo dos anos, quando estivemos na comunidade de São Pedro de Joselândia, observar, conversar a respeito da Festa e entender as relações dela com os constituintes do bem-estar apresentados pela AEM. Elaboramos um fluxograma (Figura 1) com o demonstrativo da força da relação das seis categorias do trabalho cultural com os referidos componentes de formação do bem-estar para tentar ilustrar o quão importante é a Festa de São Pedro para os moradores de São Pedro de Joselândia.

A constante realização das festas nesta comunidade é, portanto o rito mantenedor do diálogo necessário à construção de conhecimentos e partilha do título de pertença, pois:

O indivíduo se apropria do mundo em conversação com os outros e, além disso, que tanto a identidade como o mundo permanecem reais para ele enquanto ele continua a conversação. [...] O indivíduo não é modelado como uma coisa passiva, inerte. Ao contrário, ele é formado no curso de uma prolongada conversação (uma dialética, na acepção literal da palavra) em que ele é participante. Ou seja, o mundo social (com suas instituições, papéis e identidades apropriados) não é passivamente absorvido pelo indivíduo, e sim apropriado ativamente por ele (BERGER, 1985, p. 29 e 31). 


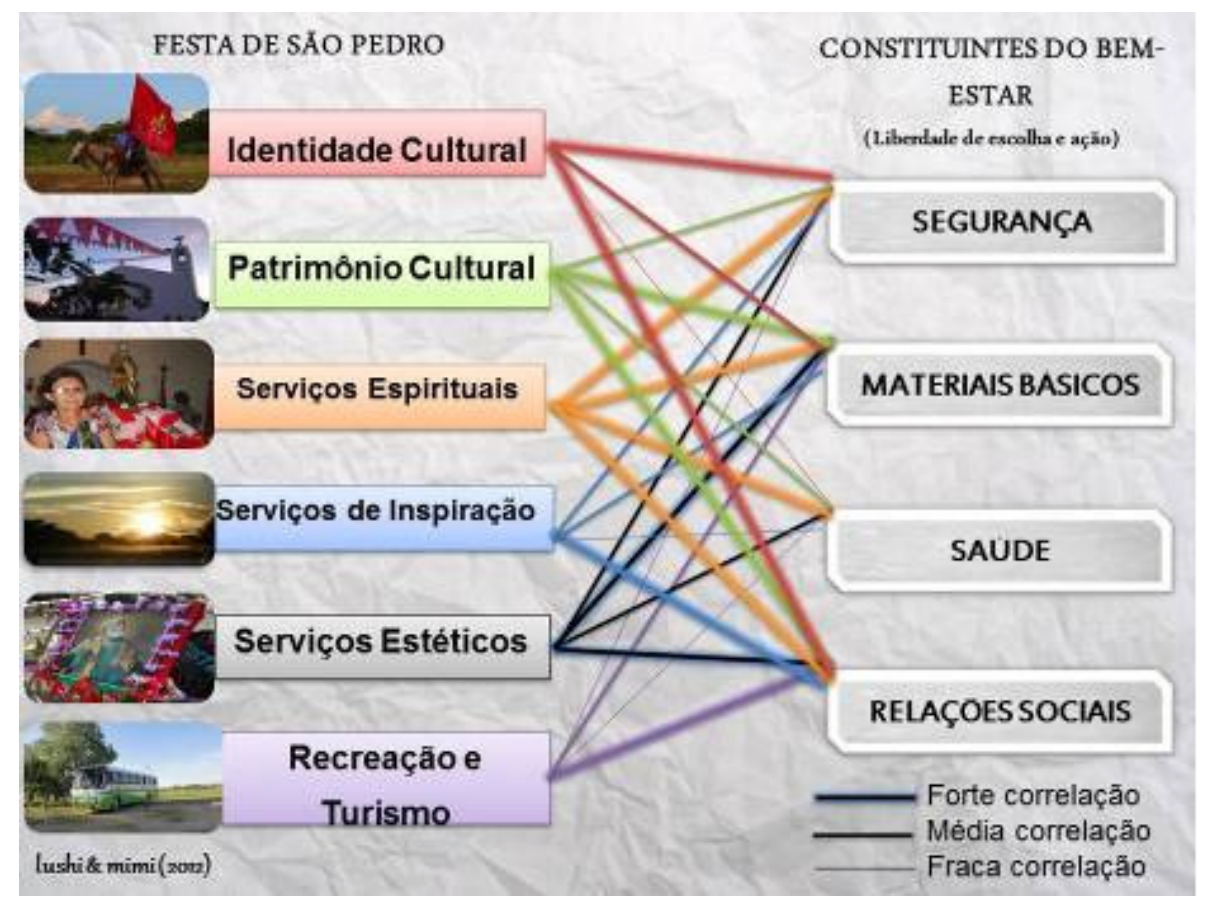

Figura 1: Ligações entre as categorias do Serviço Cultural e os constituintes do BemEstar Humano (Autora: Lucia Kawahara)

\section{Considerações}

A organização das festas revelou a presença de uma educação integral dos envolvidos da comunidade, onde coletivamente encontram táticas de manutenção da cultura e da tradição em meio às transformações resultantes do movimento da globalização e da modernidade. Foi possível observar a presença da Educação Ambiental e suas três dimensões (axiológica, epistemológica e praxiológica) em todas as atividades realizadas.

Encontramos deste modo, a desconstrução da hegemonia e construção da contra-hegemonia almejada pela Educação Ambiental. Aprendendo com os conhecimentos populares sem hierarquizar, compreendendo a dimensão e importância do vivido, da subjetividade e riqueza do saber local (SATO; PASSOS; ANJOS; GAUTHIER, 2004; GEERTZ, 2001). A pesquisa permitiunos compreender que nos espaços não escolares existem práticas educativas, por vezes, muito mais significativas do que em muitos espaços escolares. Assim, percebemos a necessidade de maior diálogo entre diferentes comunidades que permitam a transcendência dos espaços e dos currículos à construção de novas experiências, aprendizagens significativas e sonhos coletivos.

Existem também, algumas questões que necessitam ser refletidas juntamente com os próprios moradores de São Pedro de Joselândia, na coletividade, e, provavelmente nos momentos de oficinas a serem ofertados pelo grupo possamos estabelecer alguns diálogos. As festas acarretam impactos que podem e devem ser reconsiderados. Além da poluição causada 
pelos resíduos e pela sujeira pós-festa, percebemos que parece existir um enorme desperdício de comida, bem como uma dependência cada vez maior da compra direta dos alimentos ofertados na festa. Outro quesito que merece um maior entendimento é o desejo de aumentar o turismo local nas ocasiões comemorativas e, portanto, a comunidade necessita de fortalecimento e estruturação de planejamento e programas oficiais, bem como de elaborações de leis que garantam a sustentabilidade ambiental e cultural da região.

Entendendo a temporalidade e as possibilidades do vir-a-ser, não aquilo que o produto exige hoje, mas do que o processo aponta no devir do amanhã (FREIRE, 1996; SATO, 2011). O presente trabalho buscou descrever a organização das festas tradicionais que, mesmo em meio às transformações globais, a comunidade de São Pedro de Joselândia encontra novas formas de ajustamento e manutenção de sua tradição, revelando no diálogo com o nosso grupo em se pesquisar com alguns atalhos de uma cartografia investigativa:

Com a coragem de caminhar entre a ordem e a desordem num passeio que não se caracteriza como mera narrativa pessoal desprovida de ciência, mas essencialmente como busca de teorias que auxiliem a compreensão das etapas de nossas vidas, à luz da construção de identidade híbrida na educação ambiental (SATO, 2011, p. 550).

Assim, compreendemos que a sabedoria pantaneira de ser pessoas que transitam na "estrada de água" e na "estrada de chão" tem probabilidades diversas de ser e estar de forma diferenciada, desvelando criatividade e habilidades necessárias à sobrevivência neste mundo de incertezas e transformações tantas.

\begin{abstract}
Atuar no ecologismo é ter coragem de arriscar apaixonadamente numa aventura, sem temer os erros nem buscar só a vitória, mas, sobremaneira, querer escrever outra historia para que o mundo seja mais belo (SANTOS; SATO; ZANIN; MOSCHINI, 2009, p. 12).
\end{abstract}

\title{
Referências
}

ÁGUAS, C.P. Quilombo em festa - Pós-colonialismo e os caminhos da emancipação social. Coimbra: 2012. 465 fls. Tese (Doutorado). Programa de Doutoramento em Pós-colonialismo e Cidade Global. Faculdade de Economia da Universidade de Coimbra.

BAUMAN, Z. Globalização: as consequências humanas. Tradução: Carlos A. Medeiros. Rio de Janeiro: Jorge Zahar Ed., 1999.

BAUMAN, Z. Identidade: entrevista a Benedetto Vecchi. Tradução: Carlos A. Medeiros. Rio de janeiro: Jorge Zahar Ed., 2005.

Revbea, São Paulo, V. 10, N 1: 221-240, 2015. 
BHABHA, H. O local da cultura. Tradução: Myriam Ávila. Belo Horizonte: Ed. UFMG, 1998.

BERGER, P. L. O dossel sagrado: elementos para uma teoria sociológica da religião. Tradução: José Carlos Bercellos. 3ª̣ edição. São Paulo: Paulus, 1985.

CERTEAU, M., GIARD, L. e MAYOL, P. A invenção do cotidiano 2: morar, cozinhar. Tradução: Epharaim Alves e Lúcia Orth. Petrópolis, RJ: Vozes, 1996.

FREIRE, P. Pedagogia do Oprimido. 17ª ed. Rio de Janeiro: Paz e Terra, 1987.

FREIRE, P. Pedagogia da autonomia: saberes necessários à prática educativa. São Paulo: Paz e Terra, 1996.

GAUTHIER, J. A questão da metáfora, da referência e do sentido em pesquisa qualitativas: o aporte da sociopoética. Revista Brasileiras de Educação, no 25, Rio de Janeiro: 2004.

GROOT, R.; RAMAKRISHNAN, P.S., Cultural and Amenity Service. In: MEA, Millennium Ecosystem Assessment. Current State and Trade - Vol-1. New York: ONU, 2005.

GEERTZ, C. Nova luz sobre a antropologia. Tradução: Vera Joscelyne. Rio de Janeiro: Jorge Zahar Ed., 2001.

HALL, S. A identidade cultural na pós-modernidade. Tradução: Tomaz Tadeu da Silva, Guacira Lopes Louro- 11. Ed. Rio de Janeiro: DP\&A, 2006.

HERNANDEZ, F. Transgressão e mudança na educação - projetos de trabalho. Tradução: Jussara Rodriguez. Porto Alegre: ArtMed, 1998.

MATURANA, H.; DÁVILA YÁÑEZ, X. Habitar humano em seis ensaios de biologia-cultural. Tradução: Edison Cabral. São Paulo: Palas Athena, 2009.

PASSOS, L.A. Cultura: flecha humana e cósmica que aponta o caminho para os sentidos. In: GRANDO, B.S.; PASSOS, L.A. (org). O eu e o outro na escola: contribuições para incluir a história e a cultura dos povos indígenas na escola. Cuiabá: EdUFMT, 2010. P. 21 -40.

PASSOS, L.A.; SATO, M. De asas de jacarés e rabos de borboletas à construção fenomenológica de uma canoa. In: SATO, M.; CARVALHO, I. (org) Educação Ambiental: pesquisas e desafios. Porto Alegre: Artmed, 2005. p.213-232.

SANTOS, J.E.; SATO, M.; ZANIN, E.; MOSCHINI, L.E. O cenário da pesquisa no dialogo Ecológico - Educativo. São Carlos: Rima 2009.

SATO, M. (coord). Sentidos Pantaneiros: movimentos do projeto Mimoso. Cuiabá: KCM, 2002.

SATO, M. Cartografia do Imaginário no Mundo da Pesquisa. In:_ABÍLIO, F.J.P. Educação Ambiental para o Semiárido. Editora Universitária da UFPB, 2011. 
SATO, M.; GAUTHIER, J.; PARIGIPE, L. Insurgência do grupo pesquisador na educação ambiental sociopoética. In: SATO, M.; CARVALHO, I. (org) Educação Ambiental - pesquisas e desafios. Porto Alegre: Artmed, 2005.

SATO, M.; PASSOS, L.A; ANJOS, A.; GAUTHIER, J. Jogos de luzes: sombras e cores de uma pesquisa em educação ambiental. Revista de Educação Pública, v. 13, n.23, 31-55, 2004.

SATO, M.; LEITE, M.C.S.; MEDEIROS, H.; RIBEIRO, L.C. Diversidades Poéticas no Pantanal. In: SATO, M. (coord). Sentidos Pantaneiros: movimentos do projeto Mimoso. Cuiabá: KCM, 2002. p. 58 -72.

SARUKHÁN, J.; WHYTE, A. (Eds.) Millennium Ecosystem Assessment Ecosystems and Human Well-being: Biodiversity Synthesis. Washington: World Resources Institute, 2005.

SAUVÉ, L. Uma cartografia das correntes em educação ambiental. In: SATO, M.; CARVALHO, I. (org). Educação Ambiental - pesquisas e desafios. Porto Alegre: Artmed, 2005.

SILVA, R. Do invisível ao visível: o mapeamento dos grupos sociais do estado de Mato Grosso - Brasil. São Carlos: 2011. 221f. Tese (Doutorado). Programa de Pós-Graduação em Ecologia e Recursos Naturais, Universidade Federal de São Carlos.

SILVA, T.T. Documentos de Identidade: uma introdução às teorias do currículo. 8aㅡ ed. Belo Horizonte: Autêntica, 2005.

SOUZA SANTOS, B. (org). Semaear outras soluções: os caminhos da biodiversidade e dos conhecimentos rivais. Rio de Janeiro: civilização Brasileira, 2005.

TRISTÃO, M. A educação ambiental e os contextos formativos na transição de paradigmas - UFES http://www.anped.org.br/reunioes/30ra/trabalhos/GT22-3691--Int.pdf (acessado em 20/agosto/2009).

VIÉGAS, A. Complexidade: uma palavra com muitos sentidos. In: FERRARO JR., L.A. Encontros e Caminhos: Formação de Educadoras(es) Ambientais e Coletivos Educadores. Brasília: MMA/DEA, 2005. 